Revista Brasileira de Informática na Educação - RBIE

Brazilian Journal of Computers in Education

(ISSN online: 2317-6121; print: 1414-5685)

http://br-ie.org/pub/index.php/rbie

\title{
Experiência de Uso de um Aplicativo Educacional Para Dispositivos Móveis no Município de Castanhal - Pará
}

\author{
Experience of Using an Educational Application for Mobile Devices in the Municipality of \\ Castanhal
}

\author{
Paulo Sérgio Brito Pinheiro \\ Universidade Federal do Pará \\ pauluspinheiro@yahoo.com.br
}

\author{
Marcos César Da Rocha Seruffo \\ Universidade Federal do Pará \\ marcos.seruffo@gmail.com
}

\author{
Yomara Pinheiro Pires \\ Universidade Federal do Pará \\ yomara.ufpa@gmail.com
}

\section{Resumo:}

Este trabalho objetiva avaliar a experiência de uso em sala de aula de um aplicativo educacional executado em dispositivos móveis. A pesquisa configura-se como quantitativa e qualitativa de caráter empírico-exploratório, delineada como estudo de caso. O estudo envolveu um docente e vinte e dois alunos do $6^{\circ}$. ano do ensino fundamental de uma escola pública do município de Castanhal (PA) e abordou conteúdo da disciplina de matemática. Como instrumentos de coleta de dados, foram utilizados observação participante; gravação de vídeo; e aplicação de questionários após o uso do aplicativo. As análises dos dados coletados por meio dos questionários apontaram que, no contexto da pesquisa, dispositivos móveis mostraram muito atrativos aos alunos, sendo considerados produtivos para propósitos educacionais. Contudo, se observou que tais dispositivos são pouco explorados como instrumentos para estudo e aprendizagem, o que pode estar associado a cultura de proibição do celular nas escolas e a baixa proposição dos professores para uso destes equipamentos como recurso das disciplinas. A vivencia de atividade educacional realizada por meio de um jogo/aplicativo em dispositivos móveis foi muito apreciada, tendo $100 \%$ dos participantes concordado total ou parcialmente com o sentimento de envolvimento pela atividade; 95\% sentiram-se motivados para estudar o conteúdo abordado no teste; e 84,4\% consideraram a competitividade apresentada durante a atividade como elemento motivador.

Palavras-chave: Aplicativo educacional. Tecnologias educacionais. Dispositivos móveis. Gamificação

\begin{abstract}
This work intents to evaluate an experience of the use in classroom of an educational application with mobile support. This research is quantitative and qualitative, with empirical-exploratory character, designed as a case study. The study involved a teacher and twenty two students from the $6^{\text {th }}$ grade of an elementary public school from the city of Castanhal (PA) in Mathematic classes. Some instruments to collect data were used, such as participant observation, video recording and applications of questionnaires after the use of the application. The analyses of collected datas indicated that, in the context of the research, mobile devices are very attractive to the students, being considered productive to educational purposes. However, students still make low use of them as learning instruments, what may be associated to the forbidden of their use in schools and the low proposition of their use to educational purposes by teachers. The experience of an educational activity performed with a game/application in mobile devices was very appreciated by the students, with $100 \%$ of them agreeing, totally or partially, that they were involved by the activity; 95\% felt motivated to study the subjects of the classes and $84 \%$ considered the competitiveness during the game as a motivational element.
\end{abstract}

Keywords: Educational Application; Educational Technologies; Mobile Devices; Gamification.

Cite as: Pinheiro, P. S., Seruffo, M. C. da R. \& Pires, Y. P. (2019). Experience of Using an Educational Application for Mobile Devices in the Municipality of Castanhal (Experiência de Uso de um Aplicativo Educacional Para Dispositivos Móveis no Município de Castanhal - Pará). Brazilian Journal of Computers in Education (Revista Brasileira de Informática na Educação - RBIE), 27(3), 242-264. DOI: 10.5753/RBIE.2019.27.03.242 


\section{Introdução}

A presença de dispositivos móveis entre estudantes constitui uma realidade de crescimento exponencial que se evidencia a cada dia. Dados da pesquisa CGI.br-2017 (2018) apontam que 85\% da população entre 9 e 17 anos é usuária de Internet no país. Outra tendência observada nesta pesquisa é o aumento do uso de telefone celular entre crianças e adolescentes, sendo este, em muitos casos, a única opção de acesso à Internet para população jovem (CGI.br-2017, 2018). Por meio de tais dispositivos, lhes é possível divertir-se, estabelecer diálogos, ensinar, aprender e acessar informações e conteúdo de maneira rápida e prática.

Dados da Pesquisa Nacional por Amostra de Domicílios Contínua (PNADC, 2018) apontam que no Brasil, 77,1\% da população de 10 anos ou mais de idade tinha telefone móvel celular em 2016. Entre os mais jovens, 39,8\% daqueles com idade entre 10 e 13 anos e 70\% daqueles entre 14 e 17 anos possuíam telefone celular. Ao tratar especificamente a realidade dos estudantes, observou-se que $68 \%$ possuía celular, sendo $59,4 \%$ na rede pública e $90,3 \%$ na rede privada.

Estes dados demonstram a inevitabilidade da ampliação do uso de celulares no ambiente escolar e indicam a necessidade de que a escola compreenda as questões sociais e culturais relativas à cibercultura dos jovens, assim como a percepção do fenômeno como uma oportunidade de aproximação e aprendizagem mútua (Nagumo \& Teles, 2016).

Por fazerem parte do cotidiano de estudantes, os dispositivos móveis adentram em salas de aula, provocando dilema acerca da permissão, ou não, de seu uso nas escolas. Tal situação, com frequência, relaciona-se à dificuldade do professor em lidar com a utilização dos dispositivos móveis pelos alunos e o agravamento desta dificuldade tem gerado proibições formais do celular nas salas de aula. A exemplo, é possível mencionar o caso do parlamento francês que em 30 de julho de 2018 votou uma lei com o propósito de proibir o uso de celular pelos alunos em escolas públicas (Welle, 2018). No Brasil, diversos estados e municípios apresentam legislações que tratam deste mesmo tipo de proibição (Souza, 2017) e o Pará está entre os estados que apresentam legislação similar (Pará, 2009).

No contexto atual, é recorrente que se identifique estudantes com dificuldades em permanecer em sala de aula por longos períodos ou mesmo de aprender em ambientes com aulas meramente expositivas, nas quais se exige elevado nível de concentração (Mühlbeier et al., 2012). O interesse volta-se ao contato instantâneo com informações, novidades tecnológicas e às rápidas e constantes mudanças do mundo (Mühlbeier et al., 2012). Por outro lado, as estratégias pedagógicas permaneceram sem mudanças significativas durante décadas, resultando em métodos de ensino e aprendizagem em desarmonia com os interesses e necessidades dos alunos (Pereira, 2016).

Esta situação revela a necessidade de reflexão acerca das práticas pedagógicas utilizadas no cotidiano das escolas e de sua associação às tecnologias, principalmente aos dispositivos móveis. Se usados como recurso educacional, tais dispositivos representariam uma “[...] porta para um diálogo instigante entre docentes e estudantes” (Padilha, 2014, p. 81), configurando excelente oportunidade para atrair a atenção destes ao próprio processo educacional (Mühlbeier et al., 2012).

Diante do exposto, apresentar aos profissionais de educação recursos que integrem a utilização de dispositivos móveis ao processo educacional, transformando tais dispositivos em aliados dos professores e dinamizadores da formação dos alunos, passa a ser de fundamental importância para a coexistência equilibrada entre processo de ensino-aprendizado e evolução tecnológica. No intuito de abordar a problemática externada, este artigo apresenta os resultados 
de um estudo de caso baseado na experiência de uso em sala de aula de um aplicativo educacional construído em formato de jogo.

Os resultados mostrados são fruto de testes realizados com o aplicativo desenvolvido, intitulado Quizapp, e teve foco nos aspectos pedagógicos de sua utilização. Objetiva-se colaborar para a reflexão acerca do trabalho educacional voltado ao uso consciente de tecnologias pelos alunos, principalmente dos dispositivos móveis, e a introdução destes dispositivos a realidade educacional a partir da possibilidade de generalização da experiência de uso. Assim, é analisado o uso de dispositivos móveis como ferramenta de ensino-aprendizagem em sala de aula; a colaboração do uso de um aplicativo com suporte em dispositivos móveis no fortalecimento da aprendizagem; e a gamificação como elemento para melhorar o engajamento dos alunos no processo educacional.

Destaca-se que o recurso utilizado consiste num jogo em formato de quiz desenvolvido para dispositivos móveis e que devido diversidade de termos empregados na literatura para qualificar este tipo de recurso - por exemplo: app, aplicativo, aplicativo educacional, sistema, jogo, game, aplicativo móvel, software aplicativo, software educacional - neste trabalho, a título de simplificação, será utilizado o termo aplicativo.

O artigo encontra-se estruturado da seguinte forma: a seção 2 apresenta o aplicativo utilizado na pesquisa, mostrando seus principais recursos e possibilidades de uso educacional; a seção 3 aborda a metodologia de pesquisa e detalha as ferramentas utilizadas; a seção 4 apresenta os resultados alcançados com a coleta de dados, juntamente com as análises e discussões; e a seção 5 apresenta as conclusões da pesquisa.

\section{Aplicação Desenvolvida e Utilizada Nos Testes}

O aplicativo utilizado nos testes para a realização desta pesquisa foi desenvolvido pelo grupo deste artigo e foi idealizado como uma ferramenta de suporte ao trabalho educacional. Construído no formato de QUIZ, isto é, jogo em que os jogadores devem responder corretamente a questões que lhes são apresentadas, sua utilização se torna possível em qualquer disciplina e/ou modalidade de ensino.

A construção do aplicativo se deu a partir da colaboração de um grupo multidisciplinar com a participação de um estudante de bacharelado em sistemas de informação; um graduado em processamento de dados com mestrado e doutorado em engenharia elétrica; um graduado em pedagogia com especialização em informática educativa; e colaborações pontuais de professores de computação, biologia, matemática, física e português.

A construção fundamentou-se nos conceitos de aprendizagem móvel (Mobile learning), que se refere ao aproveitamento de recursos eletrônicos portáteis para uso em atividades de ensino e aprendizado (Kukulska-Hulme, 2005); gamificação, correspondente a uma abordagem que aplica elementos tipicamente usados em jogos (emoção, progressão, desafios, competição, feedbacks, recompensas, vitória, dentre outros) fora dos ambientes de jogos, com o objetivo de produzir atividades envolventes e divertidas (Kapp, 2012); e desenvolvimento web móvel, abordagem de desenvolvimento de softwares que utiliza tecnologias web projetadas para se adaptarem a dispositivos com qualquer tamanho de tela (Junior \& Bonetti, 2016).

Durante o processo de construção, o aplicativo passou por testes com alunos e professores da rede pública, tanto do ensino fundamental quanto do ensino médio, para melhoramento da ferramenta. Em cada teste foram avaliados desempenho do aplicativo; reações do professor e dos alunos diante dos recursos apresentados pelo aplicativo; e experiência de uso do aplicativo pelos alunos, tendo sido analisadas suas impressões acerca da interface do aplicativo, colaboração para 
a compreensão do conteúdo abordado, nível de satisfação com a experiência e hábitos de uso do celular para estudo.

O aplicativo apresenta similaridades visuais e de funções nas interfaces apresentadas ao professor e ao aluno, porém, há um volume maior de recursos apresentados ao professor por constituir-se o gerenciador das atividades. Abaixo são visualizadas interfaces para login e alimentação de dados (questões), correspondente ao espaço no qual o professor insere as informações que irão compor o quiz (Figura 1.a, 1.b e 1.c).

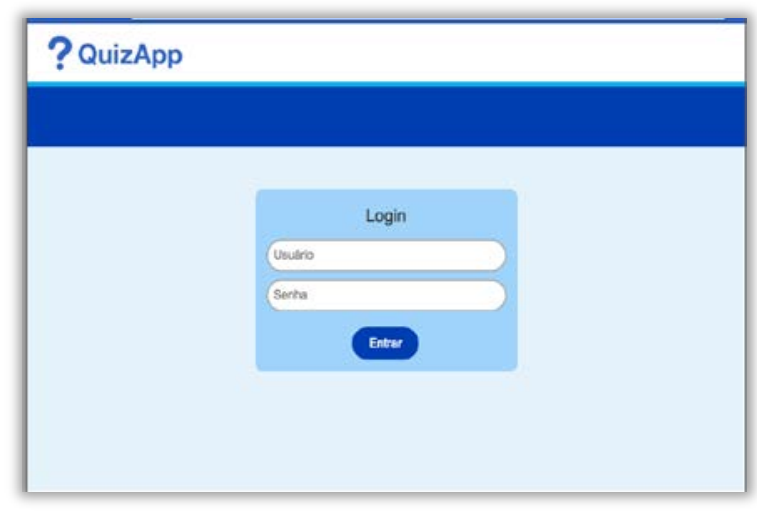

(a)

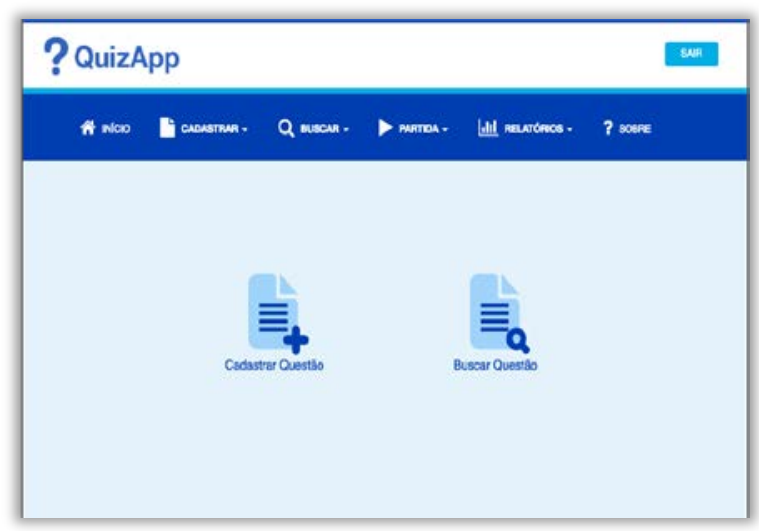

(b)

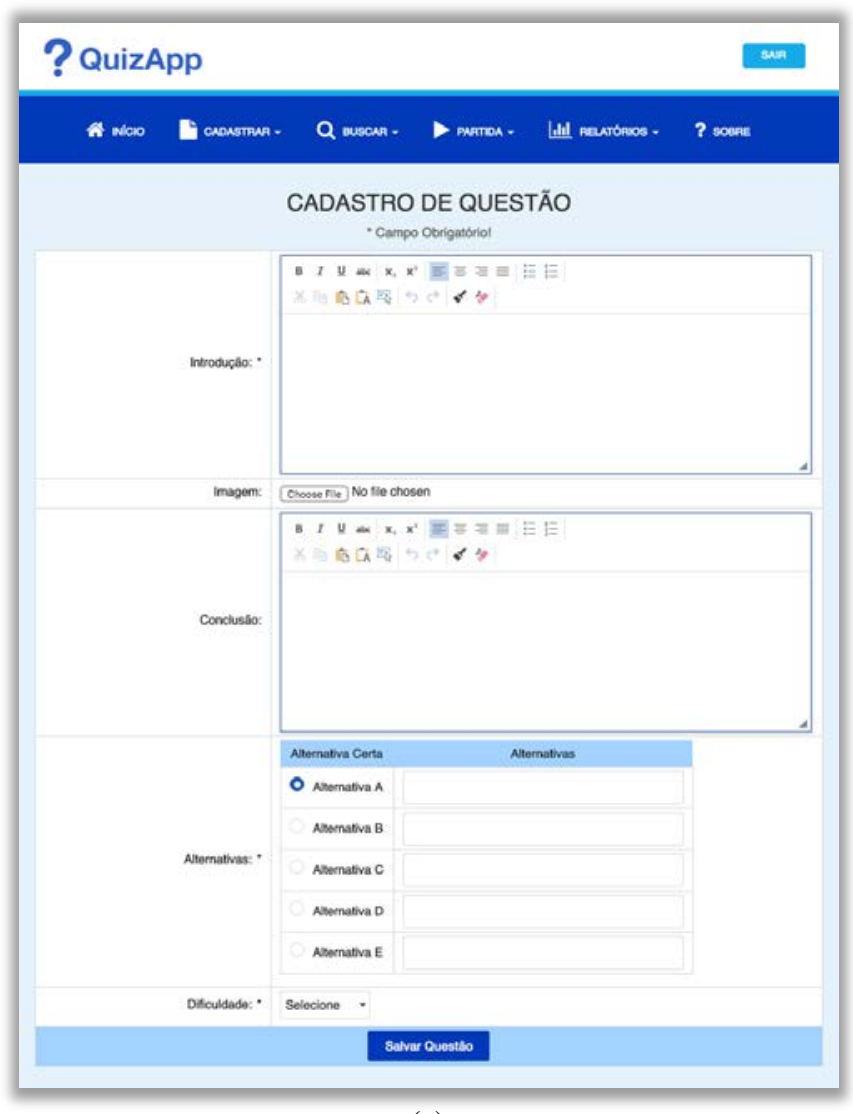

(c)

Figura 1: Interfaces do professor para login e alimentação de dados no jogo.

$\mathrm{O}$ aplicativo apresenta um recurso denominado dificuldade por meio do qual se julga o grau de complexidade apresentado pela questão-problema e se determina, por ocasião da inserção dos dados do quiz (Figura 1.c), um intervalo máximo de tempo para escolha de resposta, visto que a caixa se expande e o professor pode informar o tempo que julga necessário para resposta.

Também são disponibilizadas, para uso do professor, interfaces para administração de partidas, onde são apresentadas as questões-problemas, suas opções de resposta e o ranking (denominado placar) de todos os participantes; de encerramento, por onde se acompanha colocação, quantidade de acertos e de erros e as vantagens adquiridas ao escolher a resposta certa em menor tempo de todos os participantes (Figuras 2.a, 2.b, 2.c e 2.d). O aplicativo também suporta imagens para apoio ao conteúdo da questão-problema como item opcional ao professor.

Durante as partidas, o professor habilita aos alunos a visualização de uma questãoproblema por vez juntamente com as opções de resposta. A liberação é indicada tanto na interface do aluno quanto na do professor pela mudança de cor das opções de resposta que passam da cor cinza para a cor azul (Figura 2a e 2b; Figura 3b e 3c). Cada resposta certa corresponde a um ponto ao participante; cada resposta errada ou a não escolha de resposta corresponde a zero ponto. 


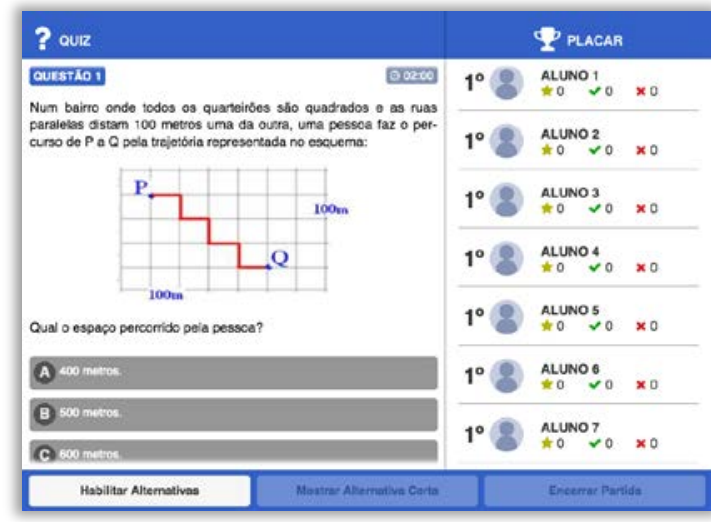

(a)

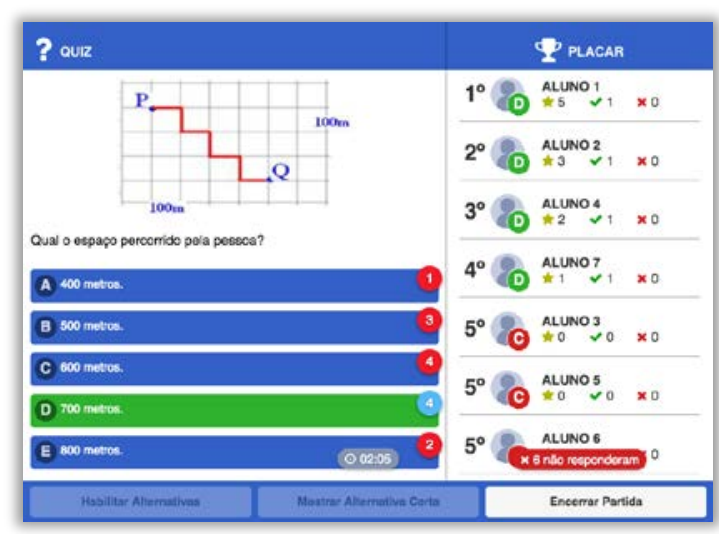

(c)

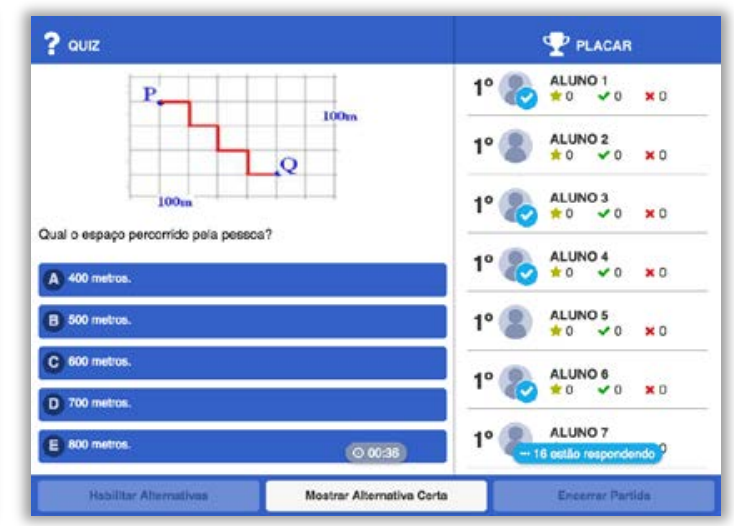

(b)

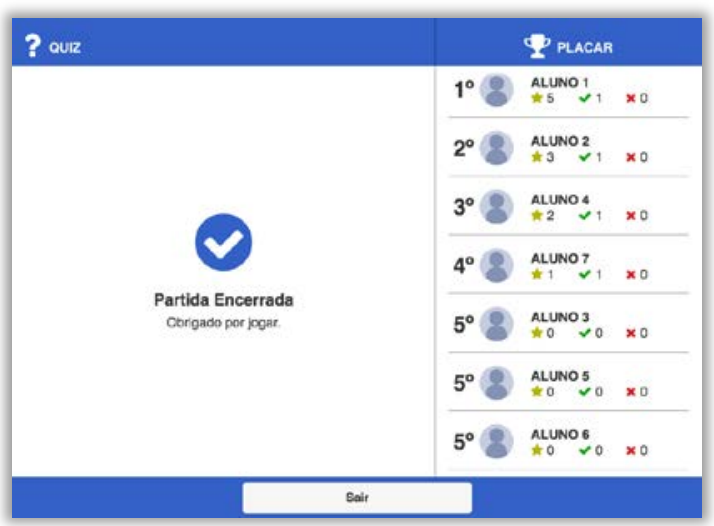

(d)

Figura 2: Interfaces do professor para administração e encerramento de partidas.

As Figuras 3.a, 3.b, 3.c e 3.d exibem as interfaces apresentadas em dispositivos móveis para login (3.a), execução (3.b e 3.c) e encerramento (3.d) de uma partida para o aluno.

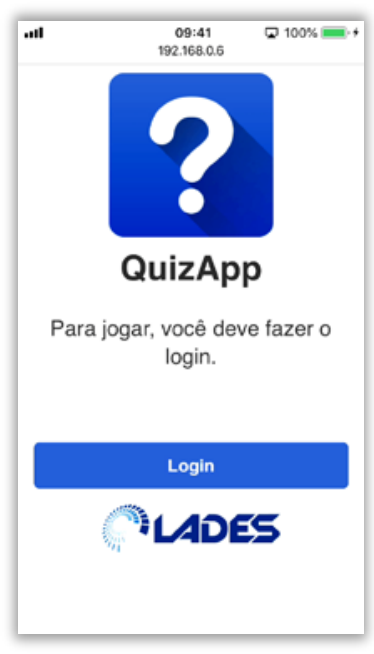

(a)

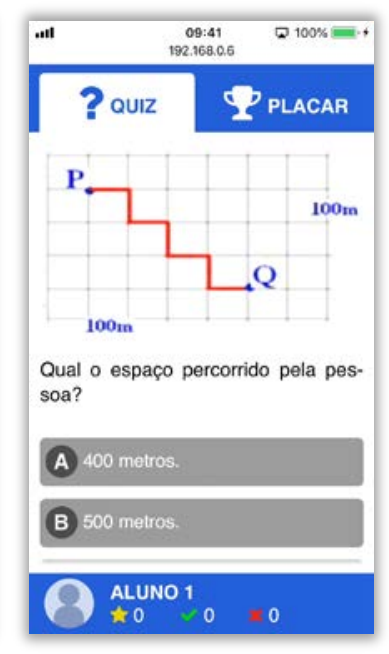

(b)

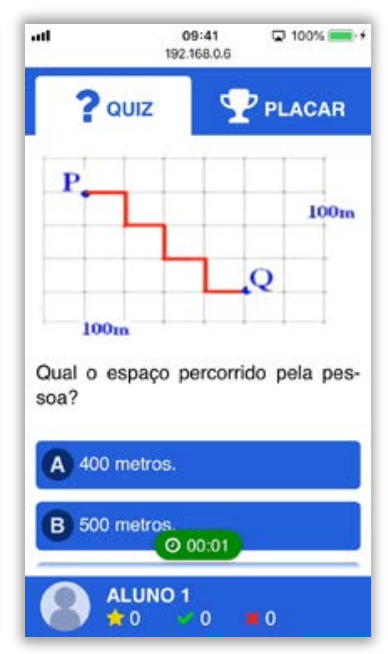

(c)

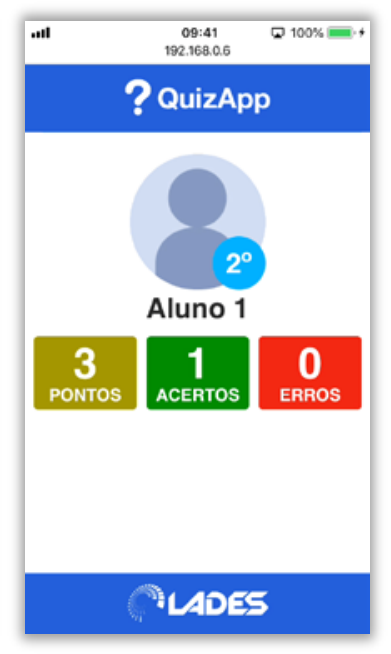

(d)

Figura 3: Interfaces do aluno para login, execução e encerramento das partidas 
O tempo é contabilizado por meio de cronômetros tanto na tela do professor quanto na do aluno. Transcorrido o tempo para escolha de resposta, fica a critério do professor estender ou não o tempo que também pode ser reduzido ao se perceber que todos os participantes já fizeram suas escolhas. Estes recursos melhoram o desempenho da capacidade cognitiva, tornando os alunos mais atentos e rápidos na resolução de problemas (Ramos \& Rocha, 2016). Além disso, fornecem ao professor um rápido feedback quanto ao alcance das metas de aprendizagem (Barbosa Neto \& Da Fonseca, 2013).

O tempo também é fator de vantagem aos participantes e quanto menor o tempo para escolha da resposta certa, maior a vantagem, indicada por um número de estrelas. É a relação entre pontos e vantagens de tempo adquiridos que gera o ranking que classifica a posição do estudante, aspectos estes oriundos da gamificação, o qual busca tornar o processo de aprendizagem mais atrativo, divertido e desafiador por meio do uso de aspectos comportamentais inerente ao ser humano como competitividade, socialização, busca por recompensas e o prazer pela superação.

Ao final da partida, o aplicativo gera relatórios no formato de planilha do Excel que contém nomes dos participantes; respostas escolhidas por cada um; colocação no ranking; pontuação alcançada; e número de erros e acertos. Estes relatórios podem dar suporte ao planejamento do docente e serem usados no processo avaliativo individual e coletivo dos alunos.

\subsection{Perspectivas para o uso pedagógico do aplicativo}

O processo de criação do aplicativo intentou uma ferramenta que pudesse, ao mesmo tempo, promover um ambiente lúdico e produzir instrumentos que auxiliassem no trabalho avaliativo do professor. Neste sentido, sua construção no formato de quiz mostrou-se capaz de atribuir diversão aos momentos de ensino. Um quiz é compreendido como recurso de entretenimento baseado em perguntas e respostas que pode ser usado como teste informal (Silva, et al., 2010). O funcionamento é feito por meio de partidas e culmina numa pontuação resultante do número de questões respondidas de modo correto (Sarinho, 2017).

Jogos são modelos de entretenimento com alto poder de atratividade e envolvimento provenientes da diversão externada pelo ato de jogar, frequentemente associada aos elementos estruturais que os compõem: regras; metas e objetivos; resultados e feedbacks; conflito/competição/desafio/oposição; interação; e representatividade por meio de contexto ou história (Prensky, 2007). Podem ser caracterizados como um sistema em que os jogadores se envolvem num desafio abstrato que, por sua vez, resulta numa saída quantificável, frequentemente gerando reações emocionais (Kapp, 2012).

O aplicativo que constitui o jogo apresenta feedbacks instantâneos provenientes da resolução dos problemas e dos resultados obtidos durante seu andamento. Tais feedbacks podem moldar o comportamento do jogador por meio da auto-avaliação e da identificação de falhas nas próprias expectativas (Gee, 2008). Já as elaborações e adaptações comportamentais que se constroem durante as tentativas de resolução dos problemas, podem mediar a aprendizagem de conceitos e ideias.

No aplicativo é possível identificar diversos recursos idealizados para fomento da diversão e que são úteis ao trabalho avaliativo. Por exemplo, a interface do professor para administração das partidas (Figura 2), ao ser visualizada pelos alunos por meio de um projetor, estimula a competitividade, produzindo maior emoção e atenção. Por meio desta interface, tão logo o professor libere a visualização da alternativa correta da questão-problema, é apresentada a quantificação da frequência de escolhas para cada opção de resposta, através de indicadores nas cores vermelha e azul. Este feedback imediato pode possibilitar ao professor, a partir de análises embasadas em sua área de formação, identificar se o conteúdo abordado na questão-problema foi 
consolidado pelo aluno ou se há dificuldades de compreensão ou aplicação de conceitos. Análises dessa natureza oportunizam ao professor desenvolver intervenções imediatas acerca de eventuais dificuldades.

Os elementos para controle e uso do tempo presentes no aplicativo são capazes de atribuir diversão e dinamismo às partidas constituindo-se em mecanismos colaboradores em alguns modelos de ensino. Seja por meio do recurso que possibilita ao professor atribuir tempo máximo para resolução das questões-problemas e que, por sua vez, produz vantagem aos alunos que executarem a atividade em menor tempo; seja por meio do cronômetro que se modifica de forma dégradé da cor verde para a cor vermelha enquanto o tempo máximo determinado pelo professor para resolução da questão-problema transcorre (observado pela variação de cor nos cronômetros), é possível utilizar o aplicativo como auxílio em formatos de ensino que utilizem tempo como fator de avaliação.

É possível identificar que, em meio educacional, se compreenda o controle de tempo como fator de desrespeito aos diversos ritmos de aprendizagem apresentados pelos alunos visto que alguns aprendem e reagem ao aprendizado mais rapidamente que outros. Neste sentido, controlar o tempo constituiria elemento para a geração de ansiedade, frustração e até a possibilidade de fracasso a alunos cujo desenvolvimento da aprendizagem se mostrasse mais lento.

Entretanto, é possível identificar que o mecanismo de controle de tempo também configure recurso útil para metodologias que objetivem o alcance de resultados - ou a resolução de problemas - em intervalos de tempo pré-determinados. Este recurso, encontrado em diversos formatos de jogos, principalmente eletrônicos, se bem introduzido e utilizado pelo professor, pode promover um ambiente lúdico para aumento da velocidade de resposta dos alunos.

Durante o jogo, é possível acompanhar, por meio de um indicador no ranking, ao lado do ícone de imagem do jogador, os alunos que escolheram ou não uma das alternativas de resposta. Assim que o professor aciona o botão para mostrar alternativa correta, finalizando a questãoproblema, o aplicativo mostra, no ranking, os participantes que a acertaram ou não, contabilizando também o número de participantes que não respondeu (Figura 2.b).

Este recurso supracitado permite ao professor inferir níveis de dificuldades para a questão ou conteúdo abordado, sugerindo-lhe ou não a retomada do conteúdo. Ressalta-se que tais inferências devem constituir-se resultado da observação das diversas reações e comportamentos apresentados pelos alunos no curso das aulas e do próprio jogo, sendo, o recurso apresentado acima, elemento de reforço às inferências.

É possível que se relacione a experiência do uso de ranking em sala de aula a um modelo educacional que reforce aspectos meritocráticos da aprendizagem. Frisa-se que a exposição dos erros e acertos dos participantes não deva ser compreendida com metodologia para hierarquização ou classificação entre indivíduos, a partir da superposição de quem acerta em detrimento da submissão de quem erra. A ocorrência da experiência positiva diante do acerto, compreendida como sucesso, ou da experiência negativa diante do erro, compreendida como fracasso, fazem parte da atividade, mas também estão presentes em aspectos do cotidiano das pessoas.

O jogo desenvolvido por meio do aplicativo constitui-se num recurso pedagógico e representa um auxílio ao processo avaliativo. Neste sentido, sua utilização deve ocorrer acompanhado de outras atividades (aulas expositivas, discussões, análises etc.) que, em tese, conduziriam (ou pelo menos, deveriam conduzir) a superação da competitividade negativa, ou seja, aquela que gera um indivíduo "bom” e outro "ruim". 
Outro aspecto que, como mencionado anteriormente, torna o aplicativo interessante ao processo avaliativo é a possibilidade de produzir relatórios no formato de planilhas acerca das partidas. Tais relatórios configuram instrumentos valiosos ao professor para avaliação minuciosa tanto individual quando da turma. Por meio dos relatórios gerados, é possível, por exemplo, atribuição de médias aos alunos; reforço na identificação das principais dificuldades de aprendizagem; e, na possibilidade do uso de questões elaboradas com base em descritores de ensino, identificar com rapidez as principais habilidades e competências desenvolvidas pela turma.

\subsection{Gamificação como experiência escolar}

A atratividade identificada em jogos diversos, capaz de fazer com que jogadores dediquem muito tempo ao desenvolvimento de habilidades para resolução de problemas relacionados aos próprios jogos (Lee \& Hammer, 2011) tem se mostrado eficaz para envolver pessoas fora de ambientes de jogos. A este movimento de utilização de aspectos constitutivos de jogos para a resolução de problemas do mundo real (Lee \& Hammer, 2011) se denominou gamificação, que corresponde ao aproveitamento de elementos de jogos fora do contexto de jogos para gerar envolvimento e produzir um comportamento desejado.

Gamificação faz parte dos elementos de análise desta pesquisa por constituir um dos referenciais conceituais utilizados na construção do aplicativo usado no levantamento de dados. É considerada um fenômeno por Remi-Omosowon et al. (2016) e pode ser encontrada em vários aspectos da vida cotidiana como no comércio, na política, na saúde e atividades físicas (Lee \& Hammer, 2011). Seu funcionamento se dá pela introdução de elementos tipicamente usados em games/jogos para gerar aprendizado e engajamento (Kapp, 2012) e promover um comportamento desejável nos indivíduos (Lee \& Hammer, 2011).

A adoção da gamificação, apesar de representar um eficiente fator de estímulos ao engajamento, introduz um componente que pode ser encarado com ressalvas em contexto educacional: a competição entre alunos. O centro da dificuldade relaciona-se ao fato da escola constituir-se em ambiente, por natureza, repleto de diferenças e desigualdades, e da ação educativa, dentre suas várias atribuições, buscar superar tais atributos. Neste cenário, a competividade, entendida como disputa, pode ser entendida como reforço as diferenças e desigualdades, visto que, em geral, centra-se na valorização de habilidades e competências muito específicas, raramente desenvolvidas pela totalidade do público alvo da escola.

Lee \& Hammer (2011) identificam que a escola apresenta diversos elementos de jogos e compreendem a vida escolar como uma forma de experiência gamificada. Os alunos ganham pontos por completarem tarefas corretamente. Tais pontos, compreendidos como recompensa, são comumente convertidos em boas notas. Também são recompensados por apresentarem comportamentos desejáveis ou punidos por comportamentos não desejáveis, o que converte recompensa e punição em moeda de troca. Se os alunos apresentarem um desempenho satisfatório ao final de um período, geralmente o ano letivo, elevam seu nível acadêmico e adentram a uma outra fase do "jogo".

Neste sentido, compreende-se que o fator competitividade explorado no jogo em decorrência de sua formação conceitual pode ser identificado como parte do cotidiano escolar, podendo ser utilizado em favor do processo educacional. Este aspecto deve ser encarado pela comunidade escolar como elemento para reflexão entre os alunos, devendo ser retomado constantemente. 


\section{Metodologia}

A pesquisa tem como objetivo avaliar uma experiência de uso em sala de aula de aplicativo educacional com suporte em dispositivos móveis. Apresenta-se como quantitativa e qualitativa, buscando, conforme Moraes (2003), o aprofundamento da compreensão acerca do fenômeno que se investiga sem a intenção de testar hipóteses para comprová-lo ou refutá-lo. É de caráter empírico-exploratório, propondo a aproximação entre pesquisador e problema a ser pesquisado (Gil, 2002). Tal formato de pesquisa tem como principal função explicitar ou construir hipóteses acerta do problema observado (Gil, 2002, p. 41).

O problema, ou foco de pesquisa, volta-se para (1) as impressões geradas no lócus pesquisado acerca do uso de aplicativo como instrumento mediador e estimulador do conhecimento; (2) a eventual colaboração do uso de dispositivos móveis neste processo e (3) o sentimento de motivação/engajamento produzido nos alunos decorrentes da experiência vivenciada. Partiu-se da premissa de que um aplicativo que explore conjuntamente conteúdos escolares; gamificação, isto é, elementos tipicamente usados em jogos; e operacionalização por meio de dispositivos móveis traz ao contexto educacional dinamismo diferenciado que produz motivação.

A pesquisa foi delineada como estudo de caso, constituindo-se numa combinação de métodos de coleta de dados, por meio dos quais são estabelecidas comparações. Para Dresch et al. (2015), estudos de caso buscam identificar o surgimento de categorias teóricas que possam servir de base para a proposição de novas teorias. Tem como principais objetivos descrever fenômenos, testar e criar teorias. O caso explorado nesta pesquisa constitui a própria experiência de uso em sala de aula do aplicativo executado em dispositivos móveis, realidade pouco vivenciada no lócus da pesquisa conforme levantamento realizado entre os participantes, reforçada pelo estigma da baixa valorização dos dispositivos móveis em ambientes escolares.

A realização da coleta de dados obedeceu às seguintes etapas: (a) pré-testes dos instrumentos de pesquisa, isto é, do aplicativo por meio do qual se realizou a atividade, e do questionário aplicado aos participantes (Gil, 2002, p. 119); (b) escolha da escola, que se deu por situar-se em perímetro urbano e atender a um público que mais facilmente seria usuário de dispositivos móveis; (c) apresentação da proposta de pesquisa ao professor participante, selecionado em virtude da manifestação de interesse pessoal na proposta metodológica do teste; (d) seleção da amostra de pesquisa, escolhida pelo professor da turma, em acordo com o pesquisador, em função de baixo desempenho e motivação; (d) apresentação da proposta aos alunos e preenchimento de Termo de Consentimento Livre e Esclarecido (TCLE) (e) e realização do teste no formato de competição entre os participantes, com premiação aos vencedores.

Foram utilizadas as seguintes ferramentas para execução do teste: (a) um computador como servidor do aplicativo, que se conectou aos celulares dos participantes por meio de uma rede wifi, sem conexão com internet, criada no ambiente da sala de aula por meio de um roteador; (b) um Datashow, usado para exibição aos alunos da tela do professor durante o jogo; (c) e uma câmera para filmagem e outra para fotografar o teste.

A coleta de dados ocorreu por meio de um teste, aplicado a uma turma de $6^{\circ}$ ano do ensino fundamental, numa escola pública do município de Castanhal, nordeste do estado do Pará. O teste correspondeu a aplicação de 14 questões de matemática, mediadas pelo Quizapp, que abordaram o conteúdo de frações, já ministrado aos participantes. As questões foram elaboradas pelo professor da turma que objetivou avaliar o conhecimento dos alunos acerca dos conteúdos abordados.

A definição do número de questões utilizadas se deu em virtude do tempo disponível para a atividade - apenas dois tempos consecutivos de 45 minutos - e pela natureza da atividade - um 
jogo - cuja processo de desenvolvimento era desconhecido pelo professor e talvez pudesse se dar de forma prolongada. Foram utilizados 13 dispositivos móveis, fornecidos pelos alunos. Participaram da atividade 22 alunos e em função do número de dispositivos não suprir o total de participantes, estes realizaram-na em dupla.

Após realização do teste, foram aplicados questionários fechados aos alunos e ao professor, por meio dos quais se buscou levantar os seguintes dados acerca dos participantes: (a) perfil socioeconômico; (b) vivências cotidianas de uso de dispositivos móveis para estudo pessoal e em sala de aula; (c) avaliação do teste enquanto atividade proposta pelo professor, desenvolvida por meio de um aplicativo para dispositivos móveis; e (d) avaliação do aplicativo. Quanto ao professor, levantou-se dados acerca de (a) tempo de formação e docência; (b) experiências de formação continuada, estudo e proposição de uso dos dispositivos móveis como ferramenta de ensino; (c) conhecimento de recursos para dispositivos móveis possíveis de serem utilizados na disciplina que ministra; (d) avaliação do aplicativo e de seu uso; (e) avaliação da turma na qual o teste foi aplicado juntamente com impressões acerca de mudanças aparentes na motivação e envolvimento com a atividade.

Salienta-se que a educação, como um processo social, está sujeita a interferências diversas que exercem influência sobre os recursos usados pelos professores. Neste sentido, o uso de um recurso educacional produz muito mais variáveis do que a capacidade científica de serem analisados. A exemplo, aspectos sociais e históricos tanto dos alunos quanto dos professores geram variáveis que exercem ação sobre o recurso durante o seu uso. Nesta pesquisa, elencaramse elementos que pudessem ser evidenciados por ocasião da atividade desenvolvida.

\subsection{Instrumentos de coleta de dados}

Esta subseção é dedicada aos instrumentos de pesquisa - questionários e observações - utilizados para a coleta dos dados, responsáveis por permitir a avaliação da experiência de uso em sala de aula do aplicativo QuizApp executado em dispositivos moveis.

\subsubsection{Questionários}

O questionário é um dos instrumentos mais tradicionais para coleta de informações. Suas principais características consistem na sua versatilidade - pode ser aplicado como instrumento de pesquisa e como ferramenta de avaliação de pessoas, processos e programas de treinamento (Muñoz, 2003); seu baixo custo, garantia de anonimato, atende finalidades específicas da pesquisa, pode abranger aspectos quantitativos e qualitativos e, sua unicidade - capacidade de apresentar as mesmas questões para todos os participantes da pesquisa, permitindo consultar rapidamente uma ampla população. Seu objetivo consiste na obtenção, sistemática e ordenada, de informações sobre a população com a qual se trabalha, sobre as variáveis que são objeto da investigação ou avaliação (Muñoz, 2003) e sobre a avaliação e julgamento de participantes de uma pesquisa acerca das variáveis pesquisadas (Nogueira, 2002).

Foram aplicados questionários aos alunos e ao professor, constituídos de questões fechadas, parte delas construídas a partir da escala de Likert. Esta escala consiste na apresentação de afirmações a respeito de um objeto de pesquisa, que são avaliadas a partir de escalas de cinco pontos, havendo num extremo a total concordância e no outro a total discordância (Nogueira, 2002). Nos questionários aplicados aos alunos, utilizou-se escalas que variaram de "Concordo totalmente" a "Discordo totalmente" e de "Péssimo/ Muito difícil” a "Excelente/ Extremamente 
Fácil”. Já no questionário aplicado ao professor, as escalas utilizadas partiram de "Péssimo/ Muito difícil" a "Excelente/ Extremamente Fácil".

\subsubsection{Questionário do aluno}

O questionário aplicado aos alunos apresentou 25 questões divididas em quatro seções com as seguintes finalidades:

- Seção I - Perfil do usuário: Por meio desta seção, buscou-se levantar dados mínimos que pudessem traçar um perfil socioeconômico dos alunos participantes da pesquisa.

- Seção II - Uso de dispositivos móveis em sala de aula: Por meio desta seção, levantou-se dados: (a) para inferência acerca da compreensão dos alunos quanto ao uso de dispositivos móveis, principalmente do celular, como recurso para autoaprendizagem dentro e fora do ambiente escolar; (b) acerca do estímulo apresentado pela escola para uso de dispositivos moveis com recurso de aprendizagem; e (c) referentes às impressões quanto ao sentimento de produtividade ou não em se usar dispositivos móveis em atividade de sala de aula, vivenciada por ocasião do teste.

- Seção III - Experiência de atividade em sala de aula por meio de um jogo: Por meio desta seção, buscou-se levantar dados acerca: (a) das impressões dos participantes quanto ao sentimento de satisfação ou insatisfação com o próprio desempenho ao realizar a atividade; (b) das impressões acerca do uso do aplicativo; (c) da colaboração ou não do fator competitividade presente no jogo; (d) do sentimento de envolvimento com a atividade.

- Seção IV - Avaliação da aplicação: Por meio desta seção, buscou-se avaliar impressões acerca do aplicativo quanto: qualidade da experiência de uso; interfaces, impressão inicial da atividade apresentada por meio do aplicativo; e a opinião acerca do conteúdo ministrado.

\subsubsection{Questionário do professor}

O questionário do professor apresentou 21 questões e objetivou levantar dados acerca: (a) do tempo de formação e docência; (b) experiências de formação continuada ou de práticas de uso de dispositivos móveis na própria disciplina; (c) concepções acerca do uso pessoal de dispositivos móveis ou pelos alunos durante as aulas; (d) conhecimentos acerca de recursos para dispositivos móveis que pudessem ser usados na própria disciplina; (e) avaliação da experiência de uso das interfaces do aplicativo utilizado na atividade; (f) avaliação da turma e possíveis diferenciais de envolvimento e motivação apresentados durante a atividade; (g) concepção pessoal acerca da uso de competitividade entre alunos em atividades de ensino; (h) e avaliação individual dos alunos participantes, baseada nos conceitos "regular”, "bom” ou “excelente”.

\subsubsection{Observações}

Este procedimento para coleta de dados consiste na utilização dos sentidos para obtenção de dados, podem ser planejadas ou não (simétricas ou assimétricas). Optou-se pela observação participante como modelo a ser seguido, tendo sido explicitado previamente ao grupo pesquisado tanto os objetivos da pesquisa quanto a identidade do pesquisador (Lüdke \& Marli, 1986). Neste tipo de observação, o pesquisador tem a oportunidade diferenciada de captar a realidade do ponto de vista de alguém "interno" ao estudo de caso, não de alguém externo a ele (Yin, 2015), dando maior plenitude de avaliação à experiência observada.

As observações foram registradas em relatórios e em vídeo gravado com consentimento do professor e dos responsáveis legais pelos alunos participantes. O questionamento principal para análise foi: de que forma o uso de um aplicativo educacional apoiado pelo celular, construído sob 
a perspectiva da gamificação, pode ser produtivo para o processo de ensino? O foco principal de análise das observações são: condições e estrutura do ambiente onde ocorreu a atividade; relação entre o professor e o aluno durante o jogo; a condução das questões pelo professor; o uso de avaliações espontâneas durante o jogo; manifestações de emoção; manifestações de competitividade; conforto ao usar o aplicativo; aproveitamento dos recursos apresentados pelo aplicativo durante a atividade; confiança e domínio em relação ao conteúdo.

\section{Resultados e discussões}

Nesta seção serão realizadas inicialmente as análises quantitativas dos dados obtidos e posteriormente apresentados a análises qualitativas. Ao final, serão discorridas discussões acerca das análises. Para maior clareza das informações, os gráficos apresentados nesta seção incluirão os dados em porcentagem e valores absolutos dos alunos.

\subsection{Perfil do usuário}

Visando estabelecer um espaço amostral representativo, a pesquisa se deu entre indivíduos com realidade semelhante a das escolas públicas em geral. A turma de $6^{\circ}$ ano em que se realizou o levantamento de dados apresenta faixa etária que variou entre 11 e 15 anos com apenas $19 \%$ de sua totalidade em idade adequada ao ano de estudo. O restante dos alunos apresentou 12 anos ou mais, indicando que a turma apresentava distorção idade-série. Do total de participantes, 72\% declararam renda familiar de até $\mathrm{R} \$ 1908,00$, com destaque para $45 \%$ que declararam renda abaixo de R\$ 954,00, indicando elevada vulnerabilidade. Os valores de remunerações apresentados no questionário tiveram como referência para cálculo, o valor do salário mínimo de 2018. Quanto ao número de pessoas na família, 59\% declararam morar com 4 pessoas ou mais. A Figura 4 sumariza os resultados da desta análise.

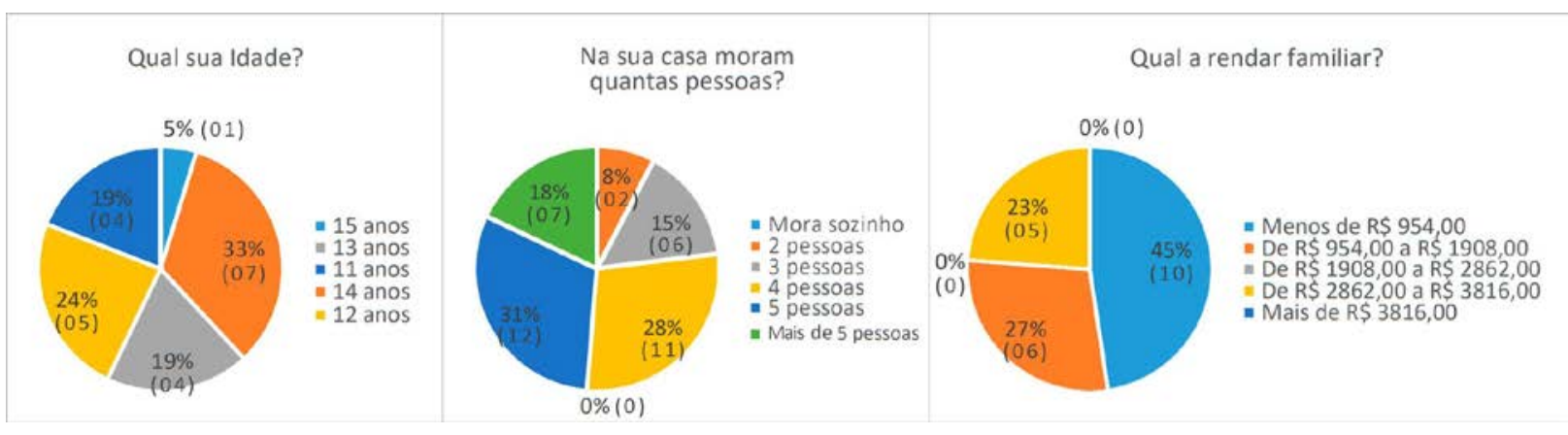

Figura 4: Resultados da seção I: Perfil sócio-econômico

\subsection{Uso de dispositivos móveis em sala de aula}

A avaliação do uso de dispositivos móveis em contexto de sala de aula também considerou experiências externas ao ambiente escolar. O primeiro elemento a ser considerado foi o uso do próprio celular pelo aluno para a realização do teste. Tal informação produziria inferências acerca da frequência de uso do celular fora do contexto de sala de aula pelo aluno, principalmente se considerada a flexibilidade para levar o dispositivo para escola, ainda que o celular declarado como próprio fosse de outra pessoa. Do total de alunos, $48 \%$ declararam ter usado o próprio celular no momento do teste, configurando expressiva parcela de participantes (Figura 5.a). 
No entanto, apesar do percentual de possuidores de celular apresentar-se como significativo, o número daqueles que os utiliza durante as aulas pode ser considerado baixo (Figura 5.b). Do total de participantes do teste, 77\% declararam nunca usar o celular enquanto os professores ministram aula, contra $21 \%$ que os utiliza às vezes e $3 \%$ que sempre os utiliza. A situação em questão pode relacionar-se a fatores diversos como, por exemplo, a proibição, pela escola, do uso do celular; a não permissão do uso do celular pelos professores e pais, associada ao temor pelas consequências em desafiá-los; ou talvez ao fato de não possuir celular. Independente do fator de impedimento, ele tende a reduzir sua influência sobre os alunos com o transcorrer dos anos, o que exigirá dos professores habilidade para lidar com tais dispositivos.

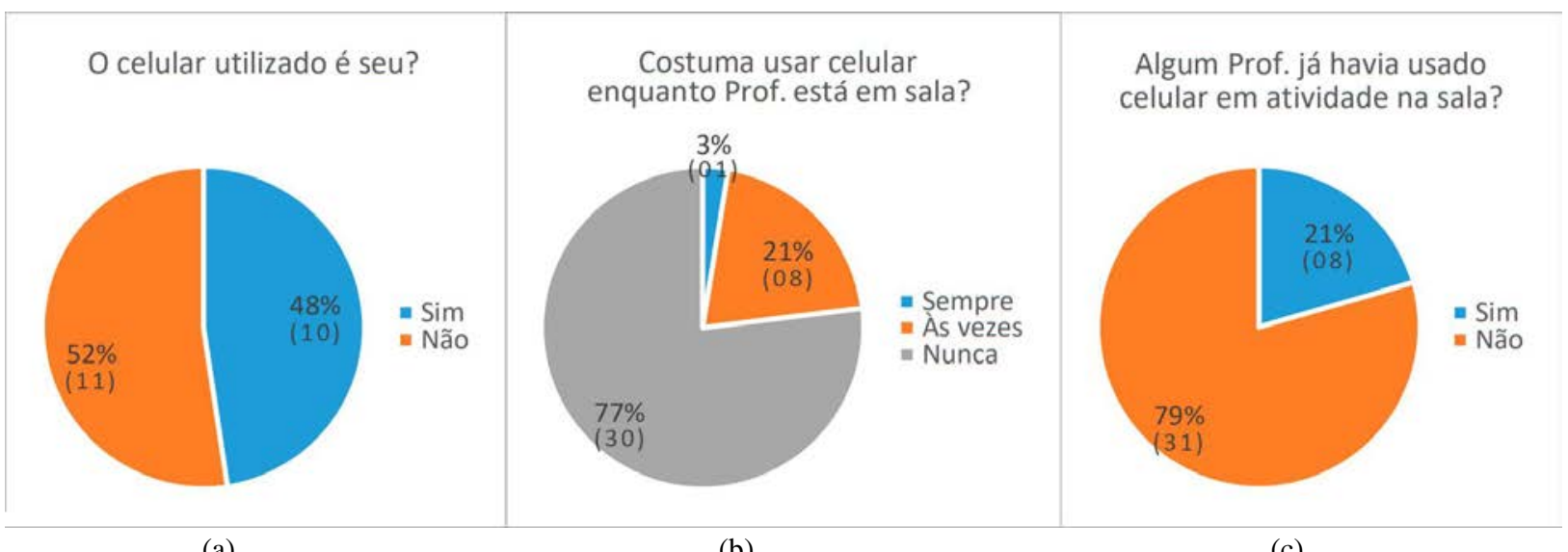

(a)

(b)

(c)

Figura 5: Dados extraídos da seção II do questionário

O aproveitamento do celular como parte da prática de ensino dos professores também foi investigado na pesquisa. Compreende-se que a ausência de proposições pela escola para o uso de dispositivos móveis durante o processo de ensino-aprendizagem colabora para um panorama que dificulta aos alunos a identificação de tais dispositivos como recursos de aprendizagem, ainda que o celular carregue em si atributos de autoaprendizagem e de exploração de informações. Para avaliar tal aproveitamento, questionou-se aos participantes acerca da proposição, pelos professores, do uso do celular em atividades de sala de aula (Figura 5.c).

O reconhecimento da não vivencia deste tipo proposição por $79 \%$ dos participantes pode ser considerado forte indicativo da cultura excludente dos dispositivos móveis no ambiente escolar. Frequentemente, tal situação é associada ao desconhecimento pelos professores de abordagens metodológicas para o uso de tais dispositivos. A ausência de estímulos, pela escola, à prática do uso do celular e dispositivos móveis em geral como recurso educacional reforça a distância entre educação formal e tais dispositivos. Neste sentido, a dificuldade de uso de um recurso já incorporado por diversas áreas da sociedade revela um descompasso entre a escola e o progresso tecnológico. Ao que se percebe, a maioria dos alunos participantes do teste parecem ainda viver esta realidade, contudo, a verificação de que 21\% (Figura 5.c) já vivenciou a proposição do uso de celular em sala de aula por um professor indica um princípio da mudança.

Outro aspecto que requer atenção é o número de alunos que usam celulares como recurso de autoaprendizagem para conteúdos escolares (Figura 6.a). Do total de participantes do teste, apenas $23 \%$ declararam sempre usar o celular como instrumento de pesquisa para as matérias da escola. Este percentual pode ser considerado baixo diante dos $48 \%$ que declararam ter usado o próprio celular durante o teste (Figura 6.a), isto é, que possivelmente tem acesso constante ao recurso. 
A situação acima poderia ser amenizada pelos 55\% que declararam às vezes usar celular como instrumento de pesquisa (Figura 6.a). No entanto, às vezes pode representar uma frequência muito baixa para um grupo de alunos entre 11 a 15 anos, com capacidade de acesso a dispositivos que já carregam em si a função de ensinar, seja através de aplicativos que reforçam aspectos do conhecimento prático, seja através da conexão com a internet, que permite a busca por qualquer tipo de informação.

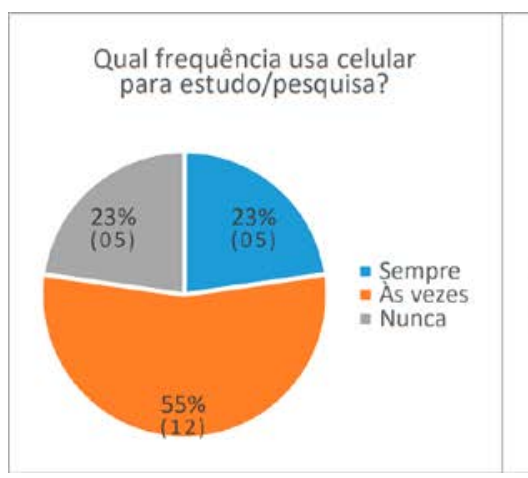

(a)

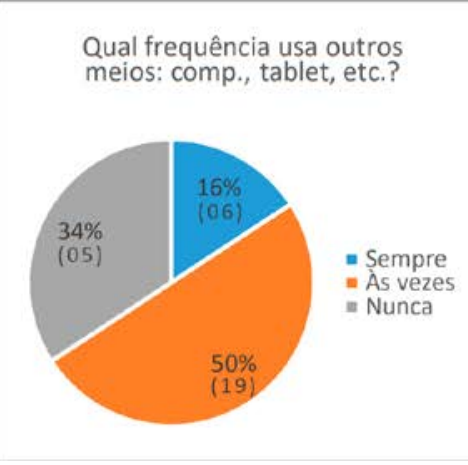

(b)

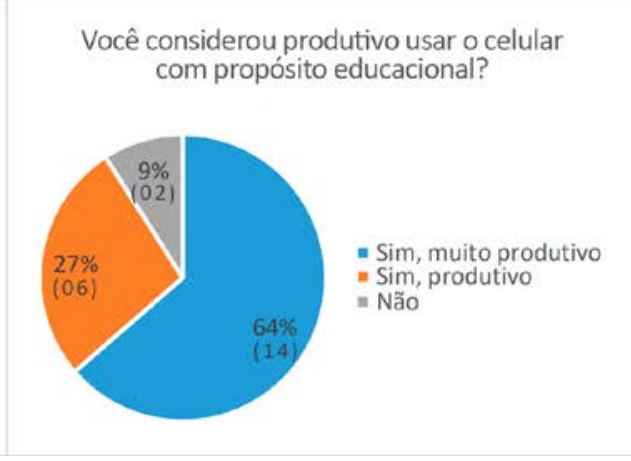

(c)

Figura 6: Dados extraídos da seção II do questionário

Do total de participantes, 23\% declararam nunca usar o celular para pesquisa das matérias da escola (Figura 6.a). Acerca desta constatação, se infere pelo menos duas possiblidades: a de que o grupo em questão não tem acesso ao celular ou que tem acesso e desassociem-no da atividade escolar, fato reforçado pela ausência de estímulos pela escola à prática do uso do celular e dispositivos móveis em geral como recurso educacional. Mesmo o uso de outros meios digitais para estudo e pesquisa não apresentaram resultados significativos (Figura 6.b). Compreende-se que ainda que os alunos não possuam em casa meios digitais para estudo, esta condição não os aparta por completo da possibilidade de acesso a este tipo de recursos. Tal condição se confirma pelos 50\% dos participantes que relataram utilizá-los as vezes.

Foi questionado aos participantes se consideraram produtivo usar o celular com propósito educacional (Figura 6.c). O objetivo seria verificar se o uso do celular poderia estar associado a um sentimento de eficiência quanto a realização do teste e aos resultados produzidos. As possibilidades de influencias para se chegar ao sentimento de produtividade ou de improdutividade seriam diversas. A exemplo, poderia ser considerado elemento produtivo a praticidade que as telas touch proporcionam a escolha de respostas ou a rapidez de feedbacks recebidos na interação com o teste/jogo/aplicativo. Por outro lado, a sensação de improdutividade poderia se associar a possibilidade de intercalar a realização da atividade com acessos a recursos recreativos presentes no celular, ou que por meio dele se tivesse acesso.

Considerou-se que ao escolher a resposta sim, muita produtivo, o participante conferiria a atividade total eficiência; ao escolher sim, produtivo, atribuiria a atividade um sucesso mediado; e ao escolher a não produtividade, o participante associaria a atividade um sentimento de ineficiência/fracasso. Do total de participantes, 64\% consideraram a atividade como muito produtiva, 27\% consideraram produtiva e 9\% não consideraram produtiva (Figura 6.c).

É possível verificar que a sensação predominante nos participantes foi a de total eficiência, tendo a maioria deles qualificado o uso do celular como muito produtivo. No entanto, faz-se necessário o reconhecimento de que $27 \%$ deles atribuiu desempenho mediano a atividade e $9 \%$ não considerou produtivo, totalizando pouco mais de um terço dos participantes.

Para corroborar com o sentimento de produtividade ou não, dois outros questionamentos foram apresentados aos participantes: um que abordava a possível distração que a atividade realizada por meio do celular pudesse provocar (Figura 7.b) e outra que avaliava a sensação de prejuízo no desempenho por usar celular durante a atividade (Figura 7.c). Compreendeu-se que a 
declaração de distração pelo participante demostraria dificuldade em concentrar-se na atividade; e o de prejuízo no desempenho, o reconhecimento de um resultado aquém do esperado.

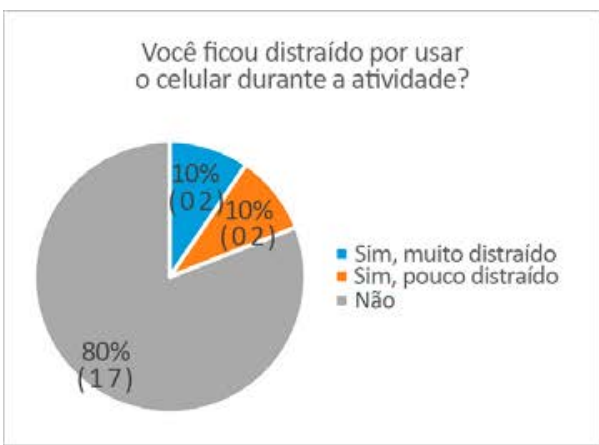

(a)

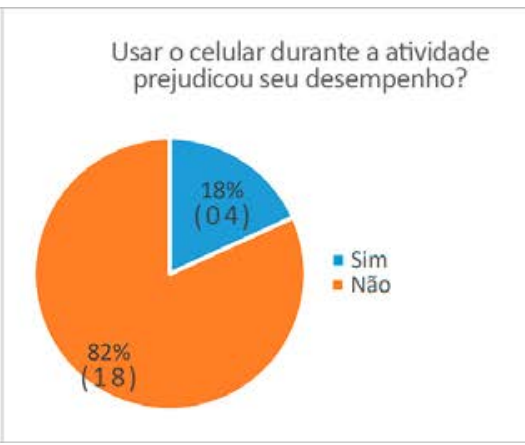

(b)

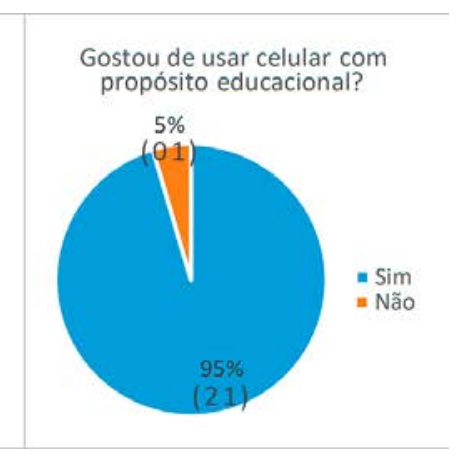

(c)

Figura 7: Dados extraídos da seção II do questionário

Quanto à possibilidade de distração durante a atividade, 81\% declararam não ter se distraído, o que pressupõe a manutenção do foco às questões e as possibilidades de respostas (Figura 7.a). Essa situação pôde ser percebida no decurso da atividade, a partir do comportamento expresso pelos alunos. No instante em que o professor liberava uma nova questão, os participantes debruçavam-se sobre o celular ou tablet, reproduzindo o comportamento habitual de realização de testes em material impresso. Ou seja, analisavam as questões com a atenção que era requerida.

Esse comportamente reforça a ideia de eficiencia na pratica do uso do celular, principalmente ao ser avaliado conjuntamente ao item que avalia a sensação de prejuízo no desempenho por realizar a atividade no celular (Figura 7.b). Neste aspecto, 82\% declararam não ter sido prejudicado, logo, que os resultados/pontuações alcançados na atividade se mostraram satisfatórios.

Para a grande maioria dos participantes do teste, a atividade em questão representou a primeira experiência de uso do celular como parte de uma atividade de sala de aula. Isso representou uma novidade e um reforço no interesse pela atividade. Quando questionados se gostaram de usar o celular com proposito educacional, 95\% deles responderam que sim (Figura 7.c).

\subsection{Experiência de atividade em sala de aula por meio de um jogo}

A gamificação representa um dos referenciais conceituais de construção do aplicativo usado no teste, tendo configurado o formato de realização do próprio teste. Dentre os objetivos deste trabalho encontra-se a verificação da interferência da gamificação durante a atividade, ou seja, da introdução de elementos tipicamente usados em games/jogos como promotores de envolvimento e engajamento.

Em razão disto, buscou-se avaliar as impressões dos participantes acerca da experiência de realizar uma atividade avaliativa por meio de um jogo, do seu envolvimento e motivação durante a atividade, e do sentimento de competitividade vivenciado por meio dela. A Tabela 1 apresenta os resultados sumarizados em itens, que constituem as questões do questionário apresentado aos participantes. 
Tabela 1: Consolidação dos dados da seção III do questionário.

\begin{tabular}{|c|c|c|c|c|c|c|}
\hline \multirow[b]{2}{*}{ Item } & \multirow[b]{2}{*}{ Afirmativas } & \multicolumn{5}{|c|}{ Respostas } \\
\hline & & $\begin{array}{l}\text { Concordo } \\
\text { totalmente }\end{array}$ & $\begin{array}{l}\text { Concordo } \\
\text { parcialmente }\end{array}$ & $\begin{array}{c}\text { Não } \\
\text { concorda } \\
\text { nem } \\
\text { discorda }\end{array}$ & $\begin{array}{c}\text { Discorda } \\
\text { parcialmente }\end{array}$ & $\begin{array}{l}\text { Discorda } \\
\text { totalmente }\end{array}$ \\
\hline 1 & $\begin{array}{l}\text { Gostei da experiência de ser avaliado por } \\
\text { meio de um jogo. }\end{array}$ & $91 \%$ & $4,5 \%$ & $0 \%$ & $0 \%$ & $4,5 \%$ \\
\hline 2 & $\begin{array}{l}\text { Competir com os colegas tornou a } \\
\text { atividade mais prazerosa. }\end{array}$ & 77,3\% & $9,1 \%$ & $9,1 \%$ & $4,5 \%$ & $0 \%$ \\
\hline 3 & $\begin{array}{l}\text { Me senti totalmente envolvido pela } \\
\text { atividade realizada durante esta aula. }\end{array}$ & $59 \%$ & $41 \%$ & $0 \%$ & $0 \%$ & $0 \%$ \\
\hline 4 & $\begin{array}{l}\text { Realizar a atividade por meio de um jogo } \\
\text { no celular me deixou mais motivado. }\end{array}$ & $81,8 \%$ & $13,6 \%$ & $0 \%$ & $0 \%$ & $4,5 \%$ \\
\hline 5 & $\begin{array}{l}\text { Realizar esta atividade me deu maior } \\
\text { motivação para me preparar (estudar) o } \\
\text { conteúdo da aula. }\end{array}$ & $80 \%$ & $15 \%$ & $5 \%$ & $0 \%$ & $0 \%$ \\
\hline
\end{tabular}

O item 1 avaliou o sentimento de satisfação dos participantes com a experiência de serem avaliados por meio de um jogo. Se considerou que a realização da atividade configurasse quebra na rotina dos estudantes, que habitualmente é constituída de elementos de avaliação de aprendizagem mas que na ocasião do teste, ocorreria sem as limitações dos recursos habituais, isto é, papel e caneta. Ainda que se apresentasse como diferenciada, por ocorrer num formato de jogo mediado pelo celular, a atividade sugerida nesta pesquisa preservou a natureza de avaliação escolar e as impressões dos participantes acerca deste aspecto necessitaram de avaliação.

Ao serem questionados acerca da experiência de avaliação por meio de um jogo (Tabela 1: item 1), é possível identificar que $91 \%$ dos participantes manifestaram o mais alto índice de satisfação com o a experiência, tendo concordado totalmente com a afirmativa sugerida. Este dado corrobora a importância de diversificar o processo avaliativo, integrando-o à tecnologia e a ludicidade (Moran, 2000) como forma de produzir interesse nos alunos. Contudo, ao se identificar que 4,5\% dos participantes manifestaram discordância total ao sentimento de satisfação, percebese que mesmo diferenciada, a atividade ainda pode mostrar-se limitada ao alcance de todos.

O item 2 avaliou o fator competitividade, intrínseco a atividade em decorrência do formato em que se apresentou aos participantes, isto é, um jogo. Tal fator é constantemente identificado na vida em sociedade e, mesmo no contexto escolar, pode ser percebido na relação entre os alunos. Por meio deste item, se buscou estabelecer uma relação entre o ato de competir com os colegas e a sensação de prazer em realizar a atividade.

É possível verificar que a maioria dos participantes concordou com a relação entre prazer com a atividade e competição com os colegas (Tabela 1: item 2), tendo 77,3\% deles concordado totalmente com a afirmativa sugerida. Logo, se identifica que para a turma na qual se realizou o teste, competir durante a atividade configurou fator positivo. No entanto, o indicativo de que $9,1 \%$ não concordou nem discordou com a afirmativa e que 4,5\% apresentou discordância parcial conduz a reflexão acerca da necessidade de se discutir este aspecto da atividade com os alunos, para que não se torne reforço ao desinteresse dos alunos.

Acerca da competitividade que se estabelece entre seres humanos, Mariotti (2000) esclarece que tal característica constitui elemento de presença constante entre os indivíduos e ressalta que, apesar de sua constância, deveria ocorrer sob a perspectiva do combate ao que o autor 
chamou de competição predatória. Para o autor, a competição predatória ressaltaria a ideia de que a sobrevivência de um indivíduo é possível somente com a eliminação do outro indivíduo com quem se compete. No contexto do jogo proposto neste trabalho, a competição predatória poderia ser expressa pelo rebaixamento e humilhação do jogador que perde, o que geraria consequências negativas para o ambiente escolar.

Como contraponto a visão de competição predatória, Mariotti (2000) indica a relação que se estabelece entre competitividade e competência, em que um indivíduo supera - vence - outro indivíduo pela melhor capacidade de coadunar conhecimentos, habilidades e atitudes. Neste concepção o vencedor estaria imbuído do dever de preservar o vencido para que este tivesse a possibilidade de também aprender a ser competente.

O item 3 avaliou a percepção dos participantes acerca do grau de envolvimento dispensado a realização da atividade (Tabela 1: item 3). O uso de gamificação em atividades diversas favorece a geração de engajamento nos participantes, o que configuraria maior envolvimento durante a atividade, atitude positiva diante do trabalho a ser desenvolvido e a busca por melhores resultados. Conforme Csikszentmihalyi (1975), diversas formas de jogo apresentam como característica a possibilidade de gerar um estado experiencial ao qual o autor denomina flow, que numa tradução livre pode ser compreendido com fluxo. Este estado, segundo o autor, denotaria uma sensação holística que tornaria um indivíduo totalmente envolvido com o desenvolvimento de uma atividade qualquer. Por meio do fluxo, se expressaria total engajamento durante a atividade, culminando em prazer e satisfação com o processo desenvolvido para realizar tal atividade. O autor informa que o tipo mais comum de experiência de fluxo é o jogo que também configura a forma mais comum de atividade lúdica.

No aspecto do sentimento de envolvimento do aluno pela atividade, se partiu da premissa de que sentir-se envolvido conduziria a uma maior atenção a atividade. Acerca deste aspecto, todos os participantes reconheceram que se mantiveram envolvimentos durante atividade, tendo a maioria, isto é 59\%, manifestado total concordância com o sentimento de envolvimento. No entanto, deve-se ressaltar que um percentual significativo deles, isto é, $41 \%$, admitiu concordância parcial a afirmativa sugerida, ou seja, dividiram sua atenção entre o teste e outras atividades não relacionadas.

O item 4 avaliou o aspecto motivacional produzido nos participantes em decorrência da realização de uma atividade escolar intermediada por um jogo no celular. Tal aspecto constitui fator de grande interesse ao se tratar de processo de ensino e aprendizagem, principalmente na educação pública. Se partiu do princípio de que a proposição desta atividade produziria motivação nos alunos, já que se identifica que a ausência de atividades diferenciadas gera desinteresse.

Quanto ao sentimento de motivação durante a atividade, alcançada pelo uso de um jogo no celular para realiza-la (Tabela 1: item 4), identifica-se a massiva concordância com a afirmativa, tendo $81,8 \%$ dos participantes concordado totalmente e $13,6 \%$ concordado parcialmente. Como já mencionado, a proposição do uso de dispositivos móveis em atividade escolar representou novidade para a grande maioria dos participantes e esse fator talvez tenha sido decisivo para determinar o grau elevado de concordâncias na relação entre jogo no celular e o sentimento de motivação. Isto representa um fator de reflexão em torno dos recursos oferecidos ou usados nas escolas para melhorar a motivação dos estudantes, reflexão esta que, em tese, deveria representar preocupação constante no ambiente educacional.

O trabalho de Tiede \& Grafe (2018) mostra que a utilização de jogos educacionais pode ajudar na motivação e engajamento dos alunos. Os resultados apresentados pelos autores indicaram que os jogos utilizados: Limitis, jogo educacional para ensino da matemática e ARTé, jogo educacional de história da arte, foram bem sucedidos em estimular a motivação e o engajamento em sala de aula com os alunos, embora os efeitos variassem entre os dois jogos em 
certos aspectos e fossem descobertos como dependentes de numerosos fatores no contexto de diferenças interpessoais.

O item 5 avaliou a capacidade motivacional da atividade em estimular nos participantes o desejo em estudar o conteúdo abordado no teste. Inferiu-se que a realização da atividade pudesse produzir tanto um sentimento de satisfação com o resultado alcançado quanto a necessidade de melhorar o próprio desempenho por meio do estudo do conteúdo. Frisa-se que os participantes foram previamente informados pelo professor de que a atividade apresentava cunho avaliativo, que conteúdos já ministrados seriam abordados, que o desempenho dos participantes produziria avaliação do aprendizado e que os resultados do jogo seriam usados na atribuição de nota. Acerca da capacidade motivacional da atividade para estimular nos participantes o desejo em estudar o conteúdo abordado no teste (Tabela 1, item 5), a quase totalidade dos participantes admitiu ter se sentido motivado, tendo $80 \%$ concordado totalmente com a afirmativa e $15 \%$ concordado parcialmente. Este aspecto motivacional da atividade pode ter sido estimulado por natureza competitiva, colaborando para a necessidade de qualificação para produzir melhor resultado, isto é, conhecer o conteúdo para ganhar mais pontos.

Tiede \& Grafe (2018) apresentaram resultados positivos sobre o aumento da motivação dos alunos em estudar o conteúdo visto em sala de aula, após interagirem com os dois jogos utilizados no trabalho. São elencados, ainda, diversos aspectos que contribuíram para o aumento das condições motivacionais, sendo alguns destes: Atenção, sendo apresentadas evidências de que os jogos atraem a atenção do usuário; Relevância, já que alguns alunos relataram que os jogos foram (em seus conteúdos ou formatos) percebidos como relevantes e positivos para suas experiências; Satisfação, visto que para alguns professores o jogo trouxe o sentimento de satisfação aos alunos que o jogaram.

\subsection{Avaliação do aplicativo}

A avaliação do aplicativo se mostrou importante por colaborar com o melhoramento da ferramenta e pela possibilidade de fornecer inferências acerca das questões anteriormente analisadas. Ocorreu por meio de uma pergunta e cinco afirmativas, conforme consolidação das Tabelas 2 e 3.

Tabela 2: Consolidação de dados da seção IV do questionário.

\begin{tabular}{c|c|c|c}
\hline PERGUNTA & \multicolumn{3}{|c}{ Respostas } \\
\hline \multirow{2}{*}{ Qual nível de dificuldade você teve para usar o aplicativo? } & $\begin{array}{c}\text { Muita } \\
\text { dificuldade }\end{array}$ & $\begin{array}{c}\text { Pouca } \\
\text { dificuldade }\end{array}$ & $\begin{array}{c}\text { Nenhuma } \\
\text { dificuldade }\end{array}$ \\
\cline { 2 - 4 } & $5 \%$ & $52 \%$ & $43 \%$ \\
\hline
\end{tabular}

A pergunta apresentada na Tabela 2 buscou avaliar a sensação de dificuldade apresentada pelos participantes ao usar o aplicativo. De modo geral, é possível perceber que a maioria identificou algum nível de dificuldade havendo prevalência para Pouca dificuldade. Considera-se que tais indicativos se relacionem a situações de instabilidade pontuais apresentadas durante o teste, em que se identificou o travamento do celular e a dificuldade na seleção de respostas, acrescido do processo inicial para carregamento do aplicativo no celular dos alunos, que ainda demanda passos de instalação não habituais. Contudo, parcela significativa dos participantes indicou Nenhuma dificuldade no uso do aplicativo. 
Tabela 3: Consolidação dos dados da seção IV do questionário.

\begin{tabular}{c|l|c|c|c|c|c}
\cline { 3 - 6 } Item & \multicolumn{1}{c|}{ Afirmativas } & $\begin{array}{c}\text { Péssimo/ } \\
\text { Muito } \\
\text { Difícil }\end{array}$ & Ruim/Difícil & $\begin{array}{c}\text { Razoável/ } \\
\text { Mediano }\end{array}$ & $\begin{array}{c}\text { Muito } \\
\text { Bom/Muito } \\
\text { Fácil }\end{array}$ & $\begin{array}{c}\text { Excelente/ } \\
\text { Extremamente } \\
\text { Fácil }\end{array}$ \\
\hline 1 & Utilizar o aplicativo foi uma experiência: & $9,5 \%$ & $9,5 \%$ & $4,8 \%$ & $52,4 \%$ & $23,8 \%$ \\
\hline 2 & A interface (telas) da aplicação é: & $4,8 \%$ & $9,5 \%$ & $38,1 \%$ & $28,6 \%$ & $19 \%$ \\
\hline 3 & A memorização da interface é: & $10 \%$ & $0 \%$ & $20 \%$ & $55 \%$ & $15 \%$ \\
\hline 4 & O início da atividade foi: & $5 \%$ & $19 \%$ & $14 \%$ & $52 \%$ & $10 \%$ \\
\hline 5 & $\begin{array}{l}\text { Em relação a aula e conteúdo ministrado } \\
\text { por meio do aplicativo. Qual sua } \\
\text { opinião? }\end{array}$ & $5 \%$ & $0 \%$ & $0 \%$ & $57 \%$ & $38 \%$ \\
\hline
\end{tabular}

A Tabela 3 apresenta itens que buscaram avaliar o aplicativo a partir de aspectos da experiência de uso. O item 1 avaliou o aplicativo considerando o sentimento de satisfação com a experiência. É possível identificar que as respostas se distribuíram entre todas as opções de escolha, porém, ainda se verifica que a maior parcela de participantes se mostrou satisfeita com o aplicativo.

Já os itens 2 e 3 avaliaram o aspecto visual das telas da aplicação, se percebendo que, em ambos os aspectos avaliados, de modo geral, houve contentamento entre os participantes, tendo, a maioria deles, escolhido as opções de respostas que atribuem avaliações favoráveis às afirmativas. Na avaliação das interfaces e no aspecto de sua memorização, respectivamente 47,6\% e 70\% dos participantes se dividiram entre Muito Bom/Muito Fácil e Excelente/ Extremamente Fácil.

Contudo, o modo como as respostas se distribuíram entre as alternativas, principalmente no item 2 em que se identifica propensão para razoável/mediano, nota-se indicativo de alerta para melhoramento dos aspectos avaliado neste item.

Acerca do item 4, que também indicou satisfação para a maioria dos participantes, se verifica que pouco mais de um terço se mostrou insatisfeito com o início da atividade. Assim como na avaliação apresentada na tabela 2, se considera que tal descontentamento esteja relacionado às dificuldades com travamentos de celular e o processo de carregamento do aplicativo nos celulares dos alunos.

Quanto ao item 5, que avaliou a aula e a ministração de conteúdo por meio do aplicativo, reafirmando dados anteriormente apresentados acerca da satisfação com o formato da atividade, se observa que a quase totalidade dos participantes também se dividiu entre as opções de respostas mais favoráveis a afirmativa apresentada. Este aspecto reitera a necessidade de se utilizar recursos tecnológicos, principalmente o celular, como elemento de engajamento aos alunos.

\section{Conclusões}

A inserção de recursos tecnológicos em contexto educacional parece constituir-se em realidade inevitável, principalmente ao se considerar o progresso constante pelo qual atravessam tais recursos e sua acelerada aceitação e incorporação em meio social. No entanto, ainda se verificam inseguranças entre professores quanto a sua incorporação em meio educacional, revelando um descompasso entre a escola e o progresso tecnológico. Ao se observar a 
incorporação de dispositivos móveis, tais inseguranças parecem acentuar-se, produzindo em alguns sistemas de ensino a proibição formal do celular no espaço da sala de aula.

Identificam-se como fortes colaboradores para esta situação as limitações de experiências em relação ao uso de dispositivos móveis como recurso pedagógico e a ausência de conhecimentos técnicos acerca das ferramentas. Como contribuição para a melhora deste quadro, o presente artigo mostrou dados extraídos a partir de uma experiência de uso de um aplicativo desenvolvido para dispositivos móveis e avaliou com foco pedagógicos os principais aspectos da experiência: o conceito de gamificação, a usabilidade e recursos do aplicativo usados para o processo educativo e as impressões dos participantes acerca da experiência.

Apesar do baixo volume de experiências de uso de dispositivos móveis como elemento de ensino e aprendizagem, 95\% dos participantes sentiram-se satisfeitos com a experiência de usálos com propósito educacional. Verificou-se que em relação a atividade avaliativa, 82\% não observaram na presença do celular um elemento de prejuízo para o seu desempenho. Observouse que a sensação predominante entre participantes foi de total eficiência em relação a atividade, tendo $91 \%$ qualificado o uso do celular como produtivo ou muito produtivo. Corroborando com o sentimento de produtividade, $81 \%$ declararam não ter se distraído por usar o celular durante a atividade, o que pressupõe a manutenção do foco às questões e às possibilidades de respostas.

Quanto a presença de competitividade, 91\% dos participantes manifestaram o mais alto índice de satisfação com o a experiência de ser avaliado por meio de um jogo no celular, 86,4\% compreenderam que a presença de competitividade tornou a atividade mais prazerosa, 95,5\% declararam que se sentiram motivados pelo formato da atividade, tendo $84,2 \%$ declarado motivação para estudar o conteúdo da aula.

Contudo, apesar dos dados mostrarem resultados satisfatórios com a experiência, não houve unanimidade ou indicativo que levasse a conclusão de que o formato da atividade tenha sido aceito pela totalidade de participantes em nenhum dos itens analisados. Neste sentido, é possível concluir que mesmo a atividade se apresentando como diferenciada para a maioria dos participantes, houve quem não se sentisse confortável, satisfeito ou incluído. Tal situação conduz a reflexão de que a utilização de qualquer recurso que subsidie o processo educacional deve configurar uma decisão de quem planeja e realiza o processo, considerando particularidades individuais dos participantes. Logo, o imperativo do uso de recursos eletrônicos durante as aulas não deve ser considerado o fator determinante para seu uso, mas um elemento a ser avaliado pelo professor. Este, por sua vez, deve possuir o aporte exigido ou minimamente necessário para utilizar tal recurso.

Frisa-se que o uso de um recurso educacional, por si só, não pode ser considerado o único fator de sucesso ou fracasso de uma atividade. Faz-se necessário que o recurso esteja alinhado a outros procedimentos e que a maioria deles apresente qualidade de elaboração e execução. Por exemplo, o uso de aplicativo para dispositivos móveis pode mostrar-se inovador e propenso a gerar motivação, porém, se usado para abordar conteúdo ministrado com baixa qualidade aos alunos, ainda que identifique motivação e engajamento durante o uso do recurso, o resultado final da atividade, isto é, o reconhecimento do aprendizado dos alunos, pode mostrar-se abaixo do esperado.

Os resultados aqui apresentados, ainda que colaborem fortemente para a reflexão do uso de tecnologias em sala de aula, mostrou-se limitado por apresentar a experiência de apenas uma turma do ensino fundamental. Faz-se necessária a avaliação deste tipo de experiência a partir da perspectiva de alunos mais jovens e mais velhos, em diferentes níveis de ensino, ou mesmo do professor que utiliza o aplicativo. Neste sentido, é pertinente considerar a realização de testes futuros para reavaliação da experiência a partir de outras visões. 


\section{Referências}

Barbosa Neto, J. F., \& Da Fonseca, F. d. (2013). Jogos educativos em dispositivos móveis como auxílio ao ensino da matemática. RENOTE, v. 11, n. 1,. DOI: $\underline{10.22456 / 1679-1916.41623}$ [GS Search]

CGI.br-2017. (2018). TIC Kids Online Brasil 2017: pesquisa sobre o uso da Internet por crianças e adolescentes no Brasil. São Paulo: Comitê Gestor da Internet no Brasil, 2018. Disponível em: https://cetic.br/media/docs/publicacoes/2/tic_kids_online_2017_livro_eletronico.pdf

Csikszentmihalyi, M. (1 de July de 1975). Play and Intrinsic Rewards. Journal of Humanistic Psychology, pp. 41-63. DOI: 10.1177/002216787501500306 [GS Search]

Dresch, A., Lacerda, D. P., \& Antunes Júnior, J. V. (2015). Design Science Research: Método de pesquisa para avanço da ciência e tecnologia. Porto Alegre: Bookman. [GS Search]

Gee, J. P. (2008). Learning and Games. Em E. b. Salen, The Ecology of Games: Connecting Youth, Games, and Learning (pp. 21 - 40). Cambridge, MA: The MIT Press. DOI: 10.1162/dmal.9780262693646.021 [GS Search]

Gil, A. C. (2002). Como elaborar projetos de pesquisa. São Paulo: Atlas. [GS Search]

Junior, L. D., \& Bonetti, T. P. (2016). Desenvolvendo Aplicações Multiplataforma para Dispositivos Móveis Utilizando Ionic e PhoneGap. XVIII Semana de Informática de Paranavaí - SEINPAR 2016. Universidade Paranaense - UNIPAR. Paranavaí. Acesso em 11 de dez. de 2017. Disponível em: http://docplayer.com.br/47915755-Desenvolvendoaplicacoes-multiplataforma-para-dispositivos-moveis-utilizando-ionic-e-phonegap.html [GS Search]

Kapp, K. (2012). The Gamification of Learning and Instruction: Game-based Methods and Strategies for Training and Education. San Francisco, CA, USA: Pfeiffer. [GS Search]

Kukulska-Hulme, A. (2005). Introduction. Em A. Kukulska-Hulme, \& J. Traxler, Mobile Learning: A handbook for educators and trainers (pp. 1 - 6). New York: Routledge. Disponível em: https://www.routledge.com/Mobile-Learning-A-Handbook-forEducators-and-Trainers-1st-Edition/Traxler-Kukulska-Hulme/p/book/9780415357395 [GS Search]

Lee, J., \& Hammer, J. (Janeiro de 2011). Gamification in Education: What, How, Why Bother? 1-5. USA. Acesso em 05/06/2018. Disponível em: https://www.researchgate.net/publication/258697764_Gamification_in_Education_What _How_Why_Bother [GS Search]

Lüdke, M., \& Marli, A. (1986). Pesquisa em educação: abordagens qualitativas. São Paulo: EPU. [GS Search]

Mariotti, H. (2000). Competitividade e Violência Estrutural. Em S. Esteves, $O$ dragão e a borboleta: sustentabilidade e responsabilidade social nos negócios (pp. 265-282). São Paulo: Axis Mundi Editora Ltda. [GS Search] 
Moraes, R. (01 de out de 2003). Uma tempestade de luz: a compreensão possibilitada pela análise textual discursiva. Ciência \& Educação, v. 9, pp. p. 191-211. Doi: 10.1590/S151673132003000200004 [GS Search]

Moran, J. M. (2000). Ensino e Aprendizagem inovadores com tecnologias audiovisuais e telemáticas. Em J. M. Moran, M. Masetto, \& M. A. Behrens, Novas tecnologias e medicação pedagógica (pp. 11-66). Campinhas - SP: Papirus. [GS Search]

Mühlbeier, A. K., Mozzaquatro, P. M., de Oliveira, L. C., Monteiro, T. B., \& Lopes, V. (out. de 2012). eNIGMA e M-Learning: Jogo Educativo Trabalhando o Raciocínio Lógico Através de Dispositivos Móveis. Revista Brasileira de Computação Aplicada, 4(2), 92-102. Doi: 10.5335/rbca.2012.2450 [GS Search]

Muñoz, T. (Marzo de 2003). El cuestionario como instrumento de investigación/evaluación. Almendralejo. Acesso em Fev. 2019. Disponível em: http://www.univsantana.com/sociologia/El_Cuestionario.pdf [GS Search]

Nagumo, E., \& Teles, L. F. (maio/ago. de 2016). O uso do celular por estudantes na escola: motivos e desdobramentos. RBEP - Revista Brasileira de Estudos Pedagógicos, 356 - 371. DOI: 10.1590/S2176-6681/371614642 [GS Search]

Nogueira, R. (2002). Elaboração e análise de questionários: uma revisão da literatura básica e a aplicação dos conceitos a um caso real. Rio de Janeiro: UFRJ/COPPEAD. [GS Search]

Padilha, M. (2014). Das tecnologias digitais à educação: nova cultura e novas lógicas para a formação docente. Em C. G. CGI.br., Pesquisa sobre o uso das Tecnologias de Informação e Comunicação nas escolas brasileiras - TIC Educação 2013 (pp. 81-86). São Paulo: Comitê Gestor da Internet no Brasil. Disponível em: https://www.cetic.br/publicacao/pesquisa-sobre-o-uso-das-tecnologias-de-informacao-ecomunicacao-nas-escolas-brasileiras-tic-educacao-2013/ [GS Search]

Pará. (08 de Mai de 2009). Lei $N^{\circ}$ 7.269, DE 6 de maio de 2009 - Dispõe sobre a proibição do uso de telefone celular, MP3, MP4, PALM. Acesso em 07 de 10 de 2017. Disponível em: Diário Oficial do Pstado do http://www.ioepa.com.br/pages/2009/2009.05.08.DOE.pdf

Pereira, J. S. (2016). Novas Tecnologias Para o Ensino: Desenvolvimento de uma aplicação em Mobile-Learning. Universidade de Lisboa. Acesso em 13 de nov. de 2017. Disponível em: http://repositorio.ul.pt/handle/10451/26263 [GS Search]

PNADC. (2018). Acesso à internet e à televisão e posse de telefone móvel celular para uso pessoal: 2016. Rio de Janeiro: IBGE. Disponível em: https://biblioteca.ibge.gov.br/visualizacao/livros/liv101543.pdf

Prensky, M. (2007). Digital game based learning. Minnesota: Paragon House. Disponível em: https://www.researchgate.net/publication/30874037_Digital_Game-Based_Learning [GS Search]

Ramos, D. K., \& Rocha, N. L. (2016). Avaliação do uso de jogos eletrônicos para o aprimoramento das funções executivas no contexto escolar. Rev. psicopedag, 33, pp. 133143. Acesso em 16 de Fev de 2019. Disponível em: 
http://pepsic.bvsalud.org/scielo.php?script=sci_arttext\&pid=S010384862016000200003\&lng=pt\&nrm=iso [GS Search]

Remi-Omosowon, A., Cant, R., \& Langensiepen, C. (2016). Applying Gamification Principles to a Container Loading System in a Warehouse Environment. Fonte: IEEE Computer society. Doi 10.1109/UKSim.2016.18 [GS Search]

Sarinho, V. T. (2017). LibrasZap - Um Jogo Baseado em Mensagens Instantâneas para Avaliação de Conhecimentos na Língua Brasileira de Sinais. Revista Brasileira de Informática na Educação - RBIE, pp. 44-59. Acesso em 10 de out de 2018. Doi: 10.5753/RBIE.2017.25.01.44 [GS Search]

Silva, J. d., Canedo, R. V., Abrantes, T. A., Santos, R. T., Souza, R. A., \& Utagawa, C. Y. (11 de out de 2010). Quiz: um Questionário Eletrônico para Autoavaliação e Aprendizagem em Genética e Biologia Molecular. Revista Brasileira de Educação Médica, pp. 607-614. Acesso em 10 de 10 de 2018. Doi: 10.1590/S0100-55022010000400017 [GS Search]

Souza, S. H. (2017). Celular em Sala de aula: De vilão à solução - Construção de atividades no contexto CTS . Universidade Federal de Ouro Preto. Instituto de Ciências Exatas e Biológicas. Mestrado Profissional em Ensino da Ciência. Programa de Pós-Graduação em Ensino da Ciência, Ouro Preto. Disponível em: https://www.repositorio.ufop.br/handle/123456789/7650 [GS Search]

Tiede, J., \& Grafe, S. (2018). Piloting two Educational Games in five European Countries: Teachers' Perceptions of Student Motivation and Classroom Engagement. 10th International Conference on Virtual Worlds and Games for Serious Applications (VSGames). Wurzburg, Germany: IEEE. Doi 10.1109/VS-Games.2018.8493438 [GS Search]

Welle, D. (2018). Parlamento francês aprova proibição dos celulares em escolas na França. Acesso em 18 de 10 de 2018, disponível em g1.globo: https://g1.globo.com/educacao/noticia/2018/07/31/parlamento-frances-aprova-proibicaodos-celulares-em-escolas-na-franca.ghtml

Yin, R. K. (2015). Estudo de caso: planejamento e métodos. Porto Alegre: Bookman. [GS Search] 